ISSN 0103-5150

Fisioter. Mov., Curitiba, v. 28, n. 2, p. 251-258, Apr./June 2015

Licenciado sob uma Licença Creative Commons DOI: http://dx.doi.org.10.1590/0103-5150.028.002.A005

\title{
Dual task performance: a comparison between healthy elderly individuals and those with Parkinson's disease
}

\author{
Desempenho em duplas tarefas entre indivíduos \\ saudáveis e com doença de Parkinson
}

\author{
Eduardo Nascimento Floriano ${ }^{[a]}$, Jacqueline Frazão Alves ${ }^{[a]}$, Isabela Andrelino de Almeida ${ }^{[a]}$, \\ Roger Burgo de Souza ${ }^{[a]}$, Gustavo Christofoletti ${ }^{[b]}$, Suhaila Mahmoud Smaili Santos ${ }^{[a] *}$ \\ [a] Universidade Estadual de Londrina (UEL), Londrina, PR, Brazil \\ [b] Universidade Federal de Mato Grosso do Sul (UFMS), Campo Grande, MS, Brazil
}

\begin{abstract}
Introduction: The dual tasks (DT) is learned during the whole life and a prerequisite in functional performance in different activities of daily living. Healthy elderly have reduced ability to perform motor activities and cognitive tasks simultaneously, compared to young adults. Parkinson's disease (PD) is the second most common neurodegenerative disease in the elderly and classic motor symptoms coexist with prejudice in cognitive domains. Objective: To compare balance, gait and performance in dual tasks of individuals with
\end{abstract}

\footnotetext{
* ENF: grad., e-mail: duh_fisio@yahoo.com.br JFA: grad., e-mail: jacquef.fisio@hotmail.com IAA: post graduate in Neurofunctional Physiotherapy, e-mail: isabelaandrelino@hotmail.com RBS: MSc, e-mail: spine@uel.br GC: PhD, e-mail: g.christofoletti@ufms.br SMSS: PhD, e-mail: suhaila@uel.br
} 
Parkinson's disease and healthy elderly. Material and method: Transversal study consisted of 21 individuals with PD, classified between 1.5 to 3 in Hoehn and Yahr scale and 21 healthy individuals. To evaluate the performance on simple tasks and dual tasks the participants were submitted to five simple tasks (motor) and each was associated with a cognitive task, featuring a DT. To balance and gait evaluation was used the following instruments: Berg Balance Scale, Tinetti Scale and Dynamic Gait Index. Results: In respect to gait and performance in dual tasks, there was a statistically significant difference with the worst performance for the group of individuals with PD. Conclusion: It was found that the group of elderly people with PD has lower performance in the execution of concurrent tasks when compared with healthy elderly, so the DT can be introduced in rehabilitation programs to improve the performance of these patients.

Keywords: Parkinson's disease. Physiotherapy. Aging. Postural balance. Gait.

\section{Resumo}

Introdução: A dupla tarefa (DT) é aprendida durante toda a vida e é pré-requisito no desempenho funcional em diversas atividades de vida diária. Idosos saudáveis apresentam redução na capacidade de executar atividades motoras e tarefas cognitivas simultaneamente, em comparação a adultos jovens. A doença de Parkinson (DP) é a segunda doença neurodegenerativa mais comum em idosos e os sintomas motores clássicos coexistem com prejuízo nos domínios cognitivos. Objetivo: Comparar o equilíbrio, a marcha e o desempenho em duplas tarefas de indivíduos com doença de Parkinson e idosos saudáveis. Material e método: Estudo transversal, composto por 21 indivíduos com DP, classificados entre os estágios 1,5 e 3 na Escala de Hoehn e Yahr e 21 indivíduos saudáveis. Para avaliação do desempenho nas tarefas simples e duplas os participantes foram submetidos a cinco tarefas simples (motoras) e a cada uma delas foi associada uma tarefa cognitiva, caracterizando uma DT. Para avaliação do equilíbrio e da marcha foram utilizados os seguintes instrumentos: Escala de Equilíbrio de Berg, Escala de Tinetti, e Índice de Marcha Dinâmica. Resultados: Não houve diferença estatisticamente significante quanto à pontuação dos grupos nas escalas de equilíbrio. Em relação à marcha e ao desempenho nas duplas tarefas, houve diferença estatisticamente significante com pior desempenho para o grupo de indivíduos com DP. Conclusões: Verificou-se que o grupo de idosos com DP apresenta menor desempenho na execução de tarefas simultâneas quando comparados com idosos saudáveis, portanto a DT pode ser introduzida nos programas de reabilitação para melhorar o desempenho desses pacientes.

Palavras-chave: Doença de Parkinson. Fisioterapia. Envelhecimento. Equilíbrio postural. Marcha.

\section{Introduction}

Dual tasking (DT), also known as simultaneous or associated tasking, is learned during an individual's entire course of life. Highly advantageous, it is a prerequisite for functional performance in various activities of daily living. A walk, for instance, enables communication between people, answering a mobile phone, or transporting objects from one place to another, among other possibilities. In normal circumstances, the simultaneous performance of cognitive and motor tasks occurs automatically; however, when there is cognitive and/or motor control impairment, greater attention is required, which may compromise the performance of both tasks $(1,2)$.
Studies addressing healthy elderly individuals report that the ability of these individuals to perform a motor task simultaneously with a cognitive task is greatly reduced when compared to young adults. Additionally, their ability to recover their balance after external interference is affected by the simultaneous performance of a secondary task $(3,4,5)$. This deficit associated with aging has been attributed to a retraction of the brain's prefrontal area, since this area performs a significant role in high-level cognitive tasks, such as memory, executive function, and dual-task performance. Recent studies report that the frontal cortex is activated during the process of learning a new motor task, e.g., a previously unknown exercise or a high-intensity exercise $(6,7)$. 
Parkinson's disease (PD) is the second most common neurodegenerative disease affecting elderly individuals: between $0.5 \%$ and $1 \%$ of the population that is between the ages of 65 and 69 years old and from $1 \%$ to $3 \%$ of the population older than 80 years old is affected. Current demographic trends indicate cases will double by $2050(8,9)$. PD is characterized by resting tremors, rigidity, plastic stiffness, bradykinesia, and postural instability $(10,11,12)$. Classic motor symptoms, however, coexist with impairment in the cognitive domains, ranging from subtle memory and attention deficits to evident dementia $(13,14,15)$.

It is well-established that reduced gait speed, reduced stride length, increased step variability, and episodes of freezing of gait are observed in people with PD when they are required to maintain a dualtask-related gait. One of the explanations for dualtask interference among patients with PD is that, when two tasks are required at the same time, one is consciously performed by the frontal cortical regions while the other is automatically controlled by the basal ganglia, the functions of which are compromised in PD patients. The task controlled by the frontal lobes may present errors and reduced speed, amplitude and strength (16).

It is important to consider that even though keeping balance seems to be a single task, it requires the integration of the sensorial, nervous, and musculoskeletal systems for the body core to be kept within a support base that is within limits of stability so that the center of gravity is moved without changing the support base. Hence, in the same way as is the case for cognitive and motor tasks, postural control occurs at the cortical level, meaning that one task interferes with the another or leads to diminished automatism (17).

Therefore, this study's aim was to compare the balance, gait and simple and dual-task performance of healthy individuals and individuals with Parkinson's disease.

\section{Material and method}

This cross-sectional study was composed of 21 individuals with Parkinson's disease cared for by the Medical Outpatient Department at Hospital das Clínicas, State University of Londrina, and 21 healthy individuals from the community, of both sexes, aged between 50 and 75 years old.
Patients with a medical diagnosis of PD classified at 1.5 and 3 stages, according to the Hoehn and Yahr Staging of Parkinson's Disease, and not hospitalized, were included in this study after formally expressing their consent by signing free and informed consent forms, in accordance with criteria established by the Institutional Review Board (Protocol No. 024/09) and Resolution 196/96, National Council of Health. Individuals with other neurological associated diseases, severe heart diseases, amputations, sensory disorders, cognitive deficits, or using orthotics or prosthesis for walking were excluded from the study.

The Hoehn and Yahr Staging of Parkinson's disease was used. It is a rapid and practical instrument that indicates the patient's general condition. In its original form, it comprised five stages of classification to assess the severity of PD based on postural instability, rigidity, tremors and bradykinesia $(18,19)$.

The following instruments were used to assess balance and gait: 1) Berg Balance Scale and the Tinetti Test, which are intended to assess balance in different activities of daily life, such as transitioning from one postural configuration to another, climbing and descending stairs, reaching for objects in front and above of oneself, and picking up fallen objects from the ground. Berg's maximum score is 56 and Tinetti's maximum score is 28, while the highest score on both scales represent the best balance $(20$, $21) ; 2)$ the Dynamic Gait Index was used to assess the individuals in different situations, such as walking at different speeds, walking while looking to the sides, up and down, traversing and walking around obstacles, climbing and descending stairs, among other situations. This scale's maximum score is 24 and indicates best balance during gait $(22,23) ; 3)$ To assess performance in simple and dual-task contexts, the participants were asked, in stage "on" of medication, to perform five simple (motor) tasks and then afterwards each of these tasks was associated with a cognitive task, characterizing motor-cognitive dualtask performance. The tasks are presented in Table 1.

In regard to the statistical analysis, the variables under study include: balance, gait, agility, simple and dual-task performance. Data are presented according to mean and standard deviation, and median and interquartile intervals, according to the distribution of normality verified by the Shapiro-Wilk test. The Mann-Whitney test was performed to study variables between groups; significance at 5\% was adopted. SPSS version 20.0 was used for data analysis. 
Table 1 - Assessing the performance of simple and dual-task

\begin{tabular}{ll}
\hline \multicolumn{1}{c}{ Simple task } & \multicolumn{1}{c}{ Dual task } \\
\hline $\begin{array}{l}\text { 1. Walk } 5 \text { meters at normal speed (timed in seconds). } \\
\text { 2. Stand-sit and sit-stand six times from a chair with } \\
\text { back (timed in seconds). }\end{array}$ & $\begin{array}{l}\text { 1. Walk } 5 \text { meters at normal speed and say the names of as many animals } \\
\text { as s/he could remember, without repeating them (timed in seconds). }\end{array}$ \\
$\begin{array}{ll}\text { 2. Stand-sit and sit-stand six times saying the names of different colors } \\
\text { (timed in seconds). }\end{array}$ \\
$\begin{array}{ll}\text { 3. Walk } 20 \text { meters at normal speed (timed in seconds). } & \begin{array}{l}\text { 3. Walk 20 meters at normal speed and answer simple mathematical } \\
\text { expressions, such as addiction, subtraction, multiplication and division } \\
\text { (timed in seconds). }\end{array} \\
\begin{array}{ll}\text { 4. Unbutton and button a shirt as fast as possible (timed } \\
\text { in seconds). }\end{array} & \begin{array}{l}\text { 4. Unbutton and button a shirt as fast as possible simultaneously saying } \\
\text { girls' names (timed in seconds). }\end{array} \\
\begin{array}{l}\text { 5. Rotate one's trunk sitting on a chair with a back, } \\
\text { holding a small ball for } 30 \text { seconds (number of }\end{array} & \begin{array}{l}\text { 5. Perform the simple task and identify figures on posters displayed on } \\
\text { the individual's left and right at every rotation (number of rotations in 30 }\end{array} \\
\text { rotations in } 30 \text { seconds). } & \text { seconds). }\end{array}$
\end{tabular}

\section{Results}

The average age found in the group with PD $(\mathrm{n}=21$ ) was $65.6 \pm 8.6$ years old; 12 individuals were male and nine were female. All the patients were classified between stages 1.5 and 3, according to the Hoehn and Yahr Stages of Parkinson's Disease. The average age in the group of healthy individuals ( $\mathrm{n}=21$ ) was $62.8 \pm 9.1$ years old; four individuals were male and 17 were female. The p-value regarding the groups' ages was 0.33 . The groups were matched according to age.

No statistically significant differences were found in regard to the scores obtained by the groups on the Berg and Tinetti scales. The scores obtained for the Dynamic Gait Index, however, showed a statistically significant difference between groups: the healthy group performed better than the group with PD (Table 2).

When comparing the outcomes, the time needed by the two groups to perform simple and dual tasks revealed statistically significant differences except for simple task 1 , simple task 2 , and dual task 2 , as shown in Table 3. The individuals with PD took longer to perform simple and dual tasks when compared to healthy individuals in the same age range.

\section{Discussion}

This study revealed that both healthy individuals and those with PD obtained similar results on the scales screening balance. This finding corroborates data obtained by Horak and collaborators (24), in which various items of the Berg Balance Scale and Tinetti test showed little or no difference in total scores among the participants in their study, who were divided into control group and group with mild PD. The authors also note that many healthcare professionals still use these scales (e.g., to predict falls) and that even patients who score well on the Berg scale and have the mild version of the disease present balance difficulties, especially when rotating, so that these signs are not measurable using the aforementioned scales. It is believed that what may explain this is the fact that these scales are sensitive to detecting compromised balance in the more advanced stages of the disease.

According to Souza (25), dual-task performance is assessed to verify cognitive processing, changes in attention mechanisms, automation of motor skills in dual tasks and to investigate diseases involving cognitive and attention deficits, such as Parkinson's disease, from experimental and behavioral perspectives.

The dual-task protocol developed in this study sought to associate daily tasks that can determine the degree of an individual's functionality, such as dressing, independent gait, and transition between postures (e.g., sitting and standing). The participants with PD took longer to perform dual tasks when compared to healthy individuals in the same age range. This finding corroborates the findings reported by the study performed by Teixeira and Alouche (26), in which individuals with PD also performed worse than the control group when asked to perform a dual task, 
which consisted of buttoning a shirt as fast as possible while saying female names. This performance may be explained by muscle rigidity, which is a typical manifestation of the disease, characterized by cocontraction between agonist and antagonist muscles. Additionally, the involvement of basal ganglia changes the speed control of voluntary movement, slowing down patients in comparison to healthy individuals when performing movements.

In the activities that involved gait, the group with PD took longer to perform their tasks when compared with the group of healthy individuals. Gait is a rhythmic and automatized action, i.e., mainly managed by subcortical systems, and, therefore, performed without attention focus. Some authors, however, assert that even gait may be harmed when performed together with another task (25). Studies show that even visual-spatial deficits common to PD manifest when walking generates an incapacity to maintain a straight path, perceive doors, obstacles and variations in terrain, possibly leading to festination, freezing and falls (27).

Table 2 - Assessment of Balance and Gait in healthy individuals and individuals with Parkinson's disease: median and interquartile interval

\begin{tabular}{lccc}
\hline & Healthy & Parkinson & p \\
\hline Berg (scores) & $55[52-56]$ & $54[52-55.5]$ & 0.32 \\
Tinetti (scores) & $26[26-27.5]$ & $25[21.5-27]$ & 0.11 \\
Dynamic Gait Index (scores) & $24[23.5-24]$ & $21[20-22]$ & $0.00^{*}$ \\
\hline
\end{tabular}

Note: *Statistically significant difference. Berg Balance Scale, Tinetti Test and DGI in points.

Table 3 - Dual-task performance of healthy individuals and individuals with Parkinson's disease: median and interquartile interval

\begin{tabular}{lccc}
\hline & Healthy & Parkinson & p \\
\hline Simple 1 (s) & $4.5[4.1-5.2]$ & $5.2[4.1-5.7]$ & 0.19 \\
Dual 1 (s) & $5[4.5-6]$ & $6.3[5-6.9]$ & $0.01^{*}$ \\
Simple 2 (s) & $16[13-16.5]$ & $16[14.3-21]$ & 0.26 \\
Dual 2 (s) & $15[13.7-19.3]$ & $18[14.4-25]$ & 0.17 \\
Simple 3 (s) & $23.4[17.8-28.2]$ & $27.4[22.4-32.7]$ & $0.04^{*}$ \\
Dual & $26.8[21-33.1]$ & $32[27.5-37]$ & $0.02^{*}$ \\
Simple 4 (s) & $25.5[13.8-35.5]$ & $41[27.4-55.7]$ & $0.002^{*}$ \\
Dual 4 (s) & $28[18.2-43.2]$ & $45[32.7-62]$ & $0.003^{*}$ \\
Simple 5 (rot) & $24[21-29]$ & $18[14-21]$ & $0.001^{*}$ \\
Dual 5 (rot) & $16[12-21]$ & $12[11-15]$ & $0.01^{*}$
\end{tabular}

Note: * Statistically significant difference. Values in (s) seconds except for the simple tasks and dual task 5 , in which number of trunk rotations (rot) were considered. 
Yogev-Seligmann et al. (28) state that patients with PD present difficulty in gait-related dual task performance but note that it is still unclear if this difficulty results from a motor or cognitive deficiency. Dual task performance creates a competition for attention and for the allocation of cognitive skills, so that one task may have priority over another, depending on the circumstances. For this reason, the authors analyzed the effects of explicit prioritization of gait or cognitive task on the speed of gait in 20 patients with PD and 20 healthy elderly individuals. The participants performed a verbal fluency task (VF) while in a sitting position as a single task and then were instructed to walk at their normal speed for 30 meters under four conditions: 1) habitual gait without a dual task, 2) walk while performing VF task without an explicit instruction to give priority to the motor or the cognitive task; 3) with an instruction to give priority to the cognitive task; and 4) with an instruction to give priority to gait. In the last two conditions, the individuals were instructed to perform the priority task as if they were being performed in isolation. As a result, individuals of both groups significantly decreased the speed of their gait while performing DT. Time of steps and time of oscillation were significantly harmed; that is, both groups took longer since neither gave priority to DT in comparison to their habitual gait. This negative effect was more evident in the group with PD.

In this line of investigation, the immediate and short time effects of a strategy that consisted of dividing attention between gait and a cognitive task for individuals with Parkinson's disease in the mild and moderate stages were investigated in a controlled clinical trial performed by Fok and collaborators (29). The participants were divided into one group $(n=6)$ that received 30 minutes of training in dual-tasks associated with cognitive tasks (walking in large steps while performing a series of subtractions) and another group $(n=6)$ who did not receive any training; instead those participants remained seated and read magazines. The individuals were initially assessed in the following conditions: 1) walking comfortably; 2) performing subtractions; and 3) walking and performing subtractions at the same time. The patients were assessed immediately after training and 30 minutes after training (retention). There was significant improvement in the length of steps and speed of gait among the individuals who received training when compared to the control group. The authors also suggest that people with PD tend to give priority to the secondary cognitive task instead of the first task when not instructed to do otherwise. Therefore, dual tasking is an appropriate strategy to improve gait, while the use of different types of secondary tasks is an alternative that may potentially lead to good results. Tseng and collaborators found similar results when they compared the performance of patients with PD while walking backwards (30).

Studies also suggest that the assessment of the ability to perform two tasks simultaneously may be a sensitive indicator of incapacity among individuals with PD, even in the initial phases of the disease. The study conducted by Fuller and collaborators (31) assessed which elements of dual tasks (cognitive or gait) are the ones most associated with deficiency and impairment in PD. A total of 154 individuals with PD were assessed under the following conditions: 1 ) time required to walk 15 meters (speed); 2) number of words generated in the verbal fluency test; and 3) association of both (dual task). The authors concluded that individuals who performed worse in the dual task than expected presented greater impairment, suggesting that patients give priority to gait performance (speed) instead of cognitive performance and that the generation of words during dual task performance may be an early and sensitive indicator of impairment in PD.

Based on evidence regarding DT performance in PD, Conradsson et al. (32) sought to investigate the effects in the short and long terms of new exercise strategies for PD and proposed, based on a controlled clinical trial, the development of a new concept for the training of balance and gait, emphasizing multitask training, associating cognitive functions (e.g., counting numbers) with secondary motor tasks (transporting and/or manipulating objects). The justification for choosing training based on motor learning is supported by recent findings regarding the phenomenon of neuroprotection induced by motor learning in patients with mild to moderate degrees of PD.

Even though results support the importance of assessment and treatment based on dual tasks for individuals with PD, one has to consider some limitations of this study: the results of a cross-sectional study are valid only for the sample under study and cannot be generalized to other samples. The choice of different dual tasks can reveal different results. Additionally, randomized clinical trials are needed 
to assess the improvement of outcomes based on treatment proposing dual task training, in addition to follow-up studies to verify how long is required for training to start presenting benefits. Despite the limitations presented, the authors were cautious in recruiting the participants and implementing the tests to ensure accuracy in the results of this study.

\section{Conclusion}

This study enabled verifying that the group of elderly individuals with Parkinson's disease performed worse than healthy individuals in simultaneous tasks and required more time to perform the same tasks. Such deficits may be related to the fact that activities that were previously automatized begin to require a controlled process when the individual began to be affected by Parkinson's disease, with increased attention demands, thereby hindering dual task performance. Studies show, however, that there is motor learning and that dual tasking may be introduced in rehabilitation programs intended to improve the performance of patients in performing these tasks, which are common tasks performed in daily life.

\section{References}

1. Teixeira NB, Alouche SR. O Desempenho da dupla tarefa na doença de Parkinson. Rev Bras Fisioter. 2007;11(2):127-32.

2. Yogev-Seligmann G, Giladi N, Brozgol M, Hausdorff JM. A training program to improve gait while dual tasking in patients with Parkinson's disease: A pilot study. Arch Phys Med Rehabil. 2012;93(1):176-81.

3. Targino VR, Freire ANF, Sousa ACPA, Maciel NFB, Guerra RO. Effects of a dual-task training on dynamic and static balance control of pre-frail elderly: a pilot study. Fisioter Mov. 2012;25(2):351-60.

4. Gehrinh PG, Bertolassi MA, Nunes MES, Basso L, Meira Júnior CM, Santos S. Desempenho em idosos em uma tarefa motora de demanda dupla de controle. Rev Bras Educ Fís Esporte. 2009;23(3):211-20.

5. Hallal CZ, Marques NR, Castro A, Spinoso DH, Rossi DM, Navega MT, et al. Variabilidade de parâmetros eletromiográficos e cinemáticos em diferentes condições de marcha em idosos. Rev Motriz. 2013;19(1):141-50.
6. Moraes H, Deslandes A, Silveira H, Arcoverde C, Alve H, Laks J. Effects of motor and cognitive dual-task performance in depressive elderly, healthy older adults, and healthy young individuals. Dement Neuropsychol. 2011;5(3):198-202.

7. Brümmer V, Schneider S, Strüder H, Askew C. Primary motor cortex activity is elevated with incremental exercise intensity. Neuroscience. 2011;181:150-62.

8. Marchi KC, Chagas MHN, Tumas V, Miasso AI, Crippa JAS, Tirapelli CR. Adesão à medicação em pacientes com doença de Parkinson atendidos em ambulatório especializado. Ciênc Saúde Coletiva. 2013;18(3):855-62.

9. Longo GS, Pinhel MS, Sado CL, Gregório ML, Amorim GS, Florim GS, et al. Exposure to pesticides and heterozygote genotype of GSTP1-Alw26I are associated to Parkinson's disease. Arq Neuropsiquiatr. 2013; 71(7):446-52.

10. Amano S, Roemmich RT, Skinner JW, Hass CJ. Ambulation and Parkinson disease. Phys Med Rehabil Clin N Am. 2013;24(2):371-92.

11. Petzinger GM, Fisher BE, McEwen S, Beeler JA, Walsh JP, Jakowec MW. Exercise-enhanced neuroplasticity targeting motor and cognitive circuitry in Parkinson's disease. Lancet Neurol. 2013;12(7):716-26.

12. Santos VV, Araújo MA, Nascimento OJM, Guimarães FS, Orsini M, Freitas MRG. Effects of a physical therapy home-based exercise program for Parkinson's disease. Fisioter Mov. 2012;25(4):709-15.

13. Christofoletti G, Cândido ER, Olmedo L, Miziara SRB, Beinotti F. Efeito de uma intervenção cognitivo-motora sobre os sintomas depressivos de pacientes com doença de Parkinson. J Bras Psiquiatr. 2012;61(2):78-83.

14. Tedrus GMAS, Fonseca LC, Kange PM. Impact of clinical and cognitive aspects on quality of life. Dement Neuropsychol. 2010;4(2):131-7.

15. Barbosa ER. Non-motor symptoms in Parkinson's disease. Arq Neuropsiquiatr. 2013;71(4):203-4.

16. Brauer SG, Woollacott $\mathrm{MH}$, Lamont $\mathrm{R}$, Clewett $\mathrm{S}$, O'Sullivan J, Silburn P, et al. Single and dual task gait training in people with Parkinson's disease: A protocol for a randomized controlled trial. BMC Neurology. 2011;11:90. 
17. Horak FB, Wrisley DM, Frank J. The Balance Evaluation Systems Test (BESTest) to differentiate balance deficits. Phys Ther. 2009;89(5):484-98.

18. Hoehn MM, Yahr MD. Parkinsonism: onset, progression and mortality. Neurology. 1967;17(5):427-42.

19. Scalzo PL, Flores CR, Marques JR, Robini SCO, Teixeira AL. Impact of changes in balance and walking capacity on the quality of life in patients with Parkinson's disease. Arq Neuropsiquiatr. 2012;70(2):119-24.

20. Miyamoto ST, Lombardi J, Berg KO, Ramos LR, Natour J. Brazilian version of the Berg balance scale. Braz J Med Biol Res. 2004;37(9):1411-21.

21. Tinetti ME. Performance-oriented assessment of mobility problems in elderly patients. J Am Geriatr Soc. 1986;34(2):119-26.

22. Jonsdottir J, Cattaneo D. Reliability and validity of the dynamic gait index in persons with chronic stroke. Arch Phys Med Rehabil. 2007;88(11):1410-5.

23. Kadivar J, Corcos DM, Foto J, Hondzinski JM. Effect of step training and rhythmic auditory stimulation on functional performance in Parkinson patients. Neurorehabil Neural Repair. 2011;25(7):626-35.

24. King LA, Mancini M, Priest K, Salarian A, Rodrigues-de-Paula F, Horak F. Do clinical scales of balance reflect turning abnormalities in people with Parkinson's disease? J Neurol Phys Ther. 2012;36(1):25-31.

25. Souza CB. Efeitos de um treinamento em condição de dupla tarefa sobre o desempenho motor e habilidade de dividir a atenção em indivíduos com doença de Parkinson [dissertação]. São Paulo: Instituto de Psicologia da Universidade de São Paulo; 2008.

26. Teixeira NB, Alouche SR. O desempenho da dupla tarefa na doença de Parkinson. Rev Bras Fisioter. 2007;11(2):127-32.
27. Galna B, Lord S, Daud D, Archibald N, Burn D, Rochester L. Visual sampling during walking in people with Parkinson's disease and the influence of environment and dual-task. Brain Res. 2012;473:35-43.

28. Yogev-Seligmann G, Rotem-Galili Y, Dickstein R, Giladi N, Hausdorff JM. Effects of explicit prioritization on dual task walking in patients with Parkinson's disease. Gait Posture. 2012;35(4):641-6.

29. Fok P, Farrell M, McMeeken J. The effect of dividing attention between walking and auxiliary tasks in people with Parkinson's disease. Hum Mov Sci. 2012;31(1):236-46.

30. Tseng I, Jeng C, Yuan R. Comparisons of forward and backward gait between poorer and better attention capabilities in early Parkinson's disease. Gait Posture. 2012;36(3):367-71.

31. Fuller RL, Van WinkleEP, Anderson KE, Gruber-Baldini AL, Hill T, Zampieri C, et al. Dual task performance in Parkinson's disease: a sensitive predictor of impairment and disability. Parkinsonism Relat Disord. 2013;19(3):325-8.

32. Conradsson D, Löfgren N, Ståhle A, Hagströmer M, Franzén E. A novel conceptual framework for balance training in Parkinson's disease study protocol for a randomized controlled trial. BMC Neurology. 2012; 12:111.

Received: 09/09/2013

Recebido: 09/09/2013

Approved: 01/27/2015

Aprovado: 27/01/2015 